\title{
Transposisi Kreatif Gerak Wayang Makidhipuh dalam Film “Setan Jawa” Karya Garin Nugroho
}

\author{
Agustina Kusuma Dewi, Yasraf Amir Piliang, Irfansyah, Acep Iwan Saidi \\ Program Studi Doktor Imu Seni Rupa dan Desain, Fakultas Seni Rupa \\ dan Desain, Institut Teknologi Bandung \\ Jalan Ganesha No. 10 Bandung \\ Tlp.085659228772, E-mail: agustinakusumadewi.3881@gmail.com
}

\begin{abstract}
Garin Nugroho's "Setan Jawa" is a film that carries a Javanese narrative story in the background, especially the beginning of the 20th century in Java. Accompaniment with live music by Rahayu Supanggah, the film was first released in 2016, and delayed on 2020 because of pandemic Covid 19. 'Movement' becomes important in this film, which is a silent film, which combines dance and puppet shadows. The 'Movement' in the film "Setan Jawa" gives a certain Javanese cultural meaning through visual movement' code, a creative transposition adapted from the wayang. Using a case study approach, this research supported by visual data analysis of Setan Jawa film documentation and literature data about puppet shadows movement' classifications by Roger Long (1979). The result identified that there were creative puppet movement transpositions made in the film 'Setan Jawa', i.e. Makidhipuh's movement. This finding reinforces the importance of adaptation and collaboration in the performing arts in the era of visual onslaught in order to maintain local culture.
\end{abstract}

Keywords: film setan jawa, garin nugroho, movement code, puppet movement

\begin{abstract}
ABSTRAK
"Setan Jawa" karya Garin Nugroho (2016) merupakan film bisu hitam putih dengan pendekatan sinematik orkestra yang diaransemen oleh Rahayu Supanggah. Mengangkat narasi awal abad ke-20 di Jawa, film ini memadukan beragam seni disiplin. 'Gerak' menjadi penting sebagai medium komunikasi, yang pada film ini di antaranya memadukan seni tari dan wayang kulit, sehingga mengandung makna kultural Kejawaan, termunculkan melalui kode visual gerak. Kode visual gerak menjadi bentuk semiosis yang salah satunya dialih-tanda dari gerak wayang kulit. Menggunakan pendekatan studi kasus didukung analisis data visual berupa dokumentasi film "Setan Jawa", dengan rujukan klasifikasi gerak pada wayang kulit yang dikembangkan dari penelitian Roger Long (1979), penelitian ini menghasilkan temuan adanya semiosis gerak yang mentransposisi gerak wayang secara kreatif pada film "Setan Jawa", salah satunya satunya, gerak makidhipuh. Transposisi gerak makidhipuh ke dalam gerak tubuh aktor pada film ini menguatkan pentingnya kolaborasi beragam tanda sebagai medium yang dapat mendukung literasi budaya secara visual di era global.
\end{abstract}

Kata kunci: film setan jawa, garin nugroho, makidhipuh, gerak wayang

\section{PENDAHULUAN}

Pada tahun 1990, dengan adanya iklan bioskop yang sudah termuat di koran-koran, pertunjukan film Indonesia bertumbuh dan berkembang melahirkan beragam film dengan bermacam tema. Selain film-film komersil yang menyasar industri, pada tahun-tahun tersebut, ada juga film-film nonkomersil 
yang lebih mengutamakan pada high-culture, permainan simbol-simbol, yang berhasil memenangkan penghargaan di mana-mana, salah satunya adalah yang dibuat oleh Garin Nugroho yang diantaranya berjudul "Bulan Tertusuk Ilalang" (FIPRESCI Film of The Year, 1996) dan kemudian dilanjutkan dengan karya berikutnya “Opera Jawa” (Piala Citra FFI untuk Skenario Adaptasi Terbaik, 2006), “Guru Bangsa: Tjokroaminoto" (Piala Maya untuk Penyutradaraan Terpilih, 2015 dan Indonesian Movie Actors Award untuk Ansambel Terbaik, 2016), serta "Kucumbu Tubuh Indahku" (Piala Citra FFI untuk Sutradara Terbaik, 2019).

Garin Nugroho, seperti yang telah disebutkan di atas, merupakan sutradara film Indonesia yang memulai karir sebagai sutradara lewat produksi film dokumenter, turut berkontribusi pada perkembangan dan kebangkitan perfilman Indonesia. Garin memiliki aspek kualitas dan kapabilitas sejumlah prestasi dengan medium, teknik dan gaya ungkapnya sendiri untuk mengekspresikan gagasannya dalam film, dan tak jarang dianggap sebagai sutradara yang memiliki estetika visual yang berbeda dengan kebanyakan sutradara film Indonesia lainnya, termasuk teknik sinematik dalam film-film buatannya (Budiman, C. dkk., 2015, hlm. 34).

Salah satu film buatannya, "Setan Jawa", merupakan film bisu hitam putih pertama karya dan disutradarai oleh Garin Nugroho, yang diiringi dengan orkestra musik gamelan secara live yang dibuat oleh Rahayu Supanggah dan diputar perdana pada September 2016 di Gedung Teater Jakarta. Perilisan film "Setan Jawa" di Jakarta merupakan penampilan pertama sebelum

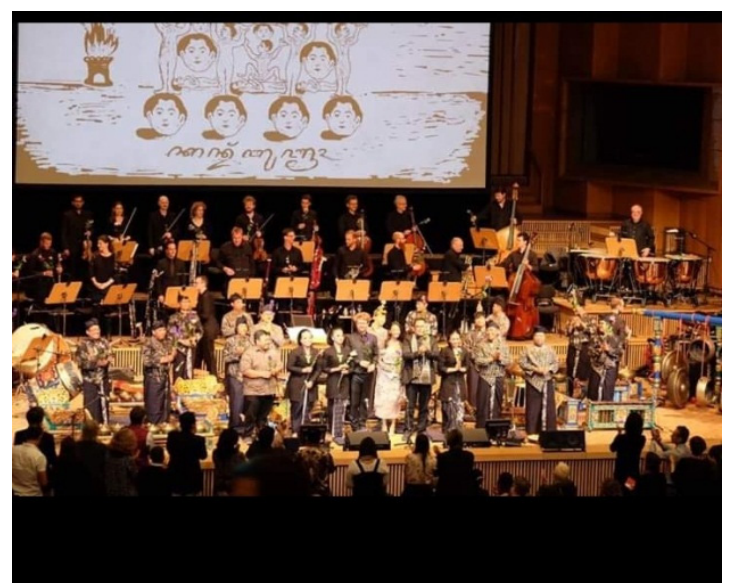

Gambar 1. Dokumentasi Pertunjukan Film "Setan Jawa".

(Diakses pada 29 Mei 2019 dari www.facebook.com/ setanjawamovie)

diputar pada world premier di Opening Night of Asia Pacific Triennial of Performing Arts di Melbourne, Februari 2017. "Setan Jawa" yang dokumentasinya ditunjukkan pada Gambar 1 mengangkat narasi besar adalah awal abad ke20 sebagai latar belakang cerita (Wawancara dengan Garin Nugroho, 2019), selaras dengan waktu tumbuhnya film hitam putih sekaligus merebaknya fashion, sastra, dan berbagai bentuk seni hiburan di puncak kolonialisme Belanda.

Film ini berkisah tentang bagaimana dua orang yang jatuh cinta tak dapat bersatu karena berbeda kasta dan tokoh laki-laki berusaha untuk mengubah nasibnya dengan mengambil jalan pesugihan yang pada era kolonial awal abad ke-20 populer untuk meraih masa depan lebih baik sekaligus sebagai mobilitas sosial dalam dunia baru yang penuh tekanan.

Era kolonial awal abad ke-20 adalah era pengembangan industrial disertai pengembangan infrastruktur bertumbuhnya gerakan nasionalisme dan juga identitas manusia Jawa yang terepresentasikan pada kehidupan sehari-hari, seni, bahasa, dan juga 
mistik. Pada era ini, mistik Jawa tumbuh seiring tumbuhnya teosofi, sebuah gerakan religiusitas berbasis harmoni beragam perspektif kepercayaan. Film ini bukanlah drama sejarah, tetapi waktu sejarah pada awal abad ke-20 di Jawa membingkai referensi pada film "Setan Jawa".

Hingga tahun 2020, film ini telah dijadwalkan tur keliling dunia dan memeroleh apresiasi positif di negara yang disinggahinya sebagai medium diskursus budaya sekaligus karya film bisu hitam putih yang dengan pendekatan sinematik-orkestra, memunculkan ruang kolaborasi antarbudaya. Sinematik-orkestra sendiri adalah term yang digunakan oleh ensembel musik yang didirikan dan disutradarai oleh Jason Swinscoe pada akhir 1990an yang mengerjakan ulang iringan musikal untuk film dokumenter sunyi yang legendaris dari tahun 1929 karya Dziga Vertov, Man with a Movie Camera (Dewi, A.K., 2019, hlm. 75).

Merujuk pada David Bordwell (1979), film berbasis high culture cenderung merupakan film seni daripada hiburan industri (Bordwell, 1997, hlm. 170) dan seperti halnya film Opera Jawa serta beberapa film Garin lainnya yang banyak bermain pada area tanda-tanda semiotika (Belasunda dkk., 2014, hlm. 110), Setan Jawa karya Garin Nugroho pun menampilkan ekspresi sineas dan lebih mementingkan misi (gagasan) sebagai alat untuk mencerdaskan 'kultur' penontonnya; meski seringkali dianggap tidak komunikatif, tidak mengikuti pakem teori film konvensional dan sulit dipahami.

'Gerak' tersebutlah yang menyadarkan seorang penonton sedang berada dalam tradisi, di mana itu meliputi ruang dan waktu tertentu dan segala bentuk pemahaman yang dimiliki sebelumnya, termasuk mengandaikan sebuah imaji bergerak secara otonom untuk membangun segala realitasnya. Realitas mengandaikan di dalamnya ada sebuah gerakan sebagai suatu yang mampu bergerak dan dapat memberikan sebuah perubahan kualitatif. Jika sesuatu yang tak bergerak nampak seakan bergerak, hal tersebut merupakan bentuk dari ilusi, yang kemudian disebut sebagai kesadaran-kamera (cameraunsconsciousness) (Deleuze, 1986, hlm. 57).

Hall (1976) menyatakan bahwa jika kita mengamati bagaimana orang-orang bergerak: apakah mereka bergerak bersama, mereka sinkron atau tidak, jenis ritme gerakan mereka, termasuk gerak mereka dalam diam, akan memberikan makna kultural tertentu (Hall, 1976, hlm. 16). Publikasi Birdwhistell's Introduction to Kinesics pada tahun 1952, menandai awal studi teknis gerakan tubuh; sejak itu, banyak orang telah dirangsang dan dipengaruhi oleh karya Birdwhistell. Salah satu dari beberapa cabang penelitian ini menunjukkan data yang sangat signifikan pada persoalan sinkroni (bergerak bersama). Menyinkronkan 'gerak' dapat berarti orang dalam interaksi bergerak bersama (secara keseluruhan atau sebagian) atau mereka tidak dan gagal melakukan gerak yang 'tersikronisasi' dan malah mengganggu orang lain di sekitar mereka. Pada dasarnya, setiap orang dalam interaksi sosial bergerak serupa gerak pada jenis tarian, tetapi 'gerak' tersebut seringkali tidak disadari sebagai gerakan sinkron yang dilakukan tanpa musik atau orkestrasi sadar. Menjadi tersinkronisasi 
dalam 'gerak' sebagai pesan tubuh (dalam atau di luar kesadaran), baik dibaca secara teknis atau tidak, adalah bentuk komunikasi.

Sejumlah ilmuwan telah bekerja pada subjek kinesik dan sinkroni dan signifikansinya. Bidang ini tumbuh semakin luas dan kompleks setiap hari, pada awal tahun enam puluhan, William Condon yang bekerja di Pennsylvania's Western State Psychiatric Institute, memulai analisis pada film $16 \mathrm{~mm}$ yang menggambarkan tokoh-tokohnya berbicara satu sama lain. Setiap gerakan, betapapun kecilnya, direkam pada selembar kertas besar sepanjang garis waktu berjalannya film (durasi), sehingga memungkinkan untuk mengidentifikasi semua gerakan yang terjadi pada saat tertentu dalam waktu.

Hasil studi tersebut mengungkapkan bahwa ketika dua orang berbicara satu sama lain, ada 'gerak' yang tersinkronisasi, kadangkadang terjadi dalam cara yang nyaris tak terlihat, terjadi secara bersamaan dan selaras dengan bagian-bagian tertentu dari kode verbal (kata-kata, dengan nada dan tekanan) ketika terurai. Melihat film dalam gerakan yang sangat lambat, mencari sinkroni, seperti yang diungkapkan oleh Lawrence Halprin, akan membuat orang menyadari bahwa apa yang dikenal sebagai tarian adalah versi turunan dari 'gerak' yang tersinkronisasi, yang sesungguhnya merupakan sebuah hidden message dalam ragam relasi sosial di masyarakat sebagai sebagian dari representasi identitas kultural. (Hall, 1976, hlm. 15-20)

Pada film Setan Jawa, 'gerak' menawarkan representasi berbeda mengenai kultur Jawa, kaitannya dengan representasi karma sebagai sebuah gerak semesta yang tak dapat dihindarkan. Merujuk pada Marcel Danesi (2004, hlm. 390) yang mendefinisikan representasi sebagai proses perekaman gagasan, pengetahuan, atau pesan secara fisik, secara lebih tepat dapat didefinisikan sebagai penggunaan tanda-tanda untuk menampilkan ulang sesuatu yang diserap, di indra, di bayangkan, atau di rasakan dalam bentuk fisik, Setan Jawa pun menggunakan tandatanda 'gerak' yang dibangun dari beragam bentuk kesenian, sehingga seluruh aspek visual dalam film, kemudian menjadi praktek penting yang memproduksi kebudayaan.

Dalam hal ini, pencitraan adalah perantara untuk realisasi gagasan, 'bahasa' dalam film dapat membawa orang kembali ke kekuatan kreatif orang untuk merekonstruksi gagasan dalam imajinasi nyata. Dalam film, sebuah gambar menjadi bagian penting yang tidak dapat dipisahkan. Tanpa gambar film bukanlah seni memutar gambar di layar. Gambar pada titik ini sangat penting dalam sebuah film (Sugiharto, B. 2013, hlm. 308). Film, kemudian, dikaitkan dengan media wacana sosial dan memiliki karakteristik unik yang menyebar ke berbagai tempat, sedangkan dari perspektif psikoanalisis film berpotensi untuk bermain di pikiran bawah sadar sehingga dapat menjadi kekuatan hipnosis budaya massa, memengaruhi cara berpikir yang terkait erat dengan persepsi dan kesesuaian nilai-nilai di mana informasi dikomunikasikan. Film, kemudian, dengan sifat multiliterasinya, berpotensi sebagai medium edukasi budaya.

Film sine-orkestra merupakan salah satu bentuk komunikasi grafis yang masih jarang dilakukan di Indonesia. Film sine-orkestra 
"Setan Jawa" merupakan film bisu hitam putih pertama karya Garin Nugroho yang diiringi dengan orkestra musik gamelan secara live yang dibuat oleh Rahayu Supanggah dan diputar perdana pada September 2016 di Gedung Teater Jakarta. Hingga tahun 2020, film ini masih dijadwalkan tur keliling beberapa Negara. Setan Jawa yang dokumentasinya ditunjukkan pada Gambar 1 mengangkat kisah mitologi Jawa Pesugihan Kandang Bubrah sebagai narasi besar, termasuk di dalamnya adalah diakronik kebudayaan masyarakat Jawa di awal abad ke-20 yang divisualisasikan melalui karakter yang bermain dalam film, Asih (Asmara Abigail), Setio (Heru Purwanto), Ibu Asih (Quin Dorothea), dan Setan Jawa (Luluk Ari).

Seringkali dianggap tidak komunikatif dan tidak mengikuti teori film konvensional, film berbasis high culture, seperti halnya film Opera Jawa dan beberapa film Garin lainnya yang banyak bermain pada area tanda-tanda semiotika. Setan Jawa karya Garin Nugroho lebih mementingkan misi (gagasan) sebagai alat untuk mencerdaskan 'kultur' penontonnya serta menampilkan ekspresi sineas dan dengan sifatnya yang sine-orkestra, film Setan Jawa menjadi sebuah medium diskursus budaya, yang memberikan ruang bagi pertumbuhan sirkulasi maknamakna, objek-objek, dan identitas kultural yang terbangun dalam ruang dan waktu yang difusif sebagai dampak dari perkembangan teknologi digital. (Irfansyah dan Sunarto, 2013, hlm.15-26)

Seringkali perkembangan teknologi pada era gempuran visualisasi saat ini memerlukan modifikasi gagasan yang terimplementasikan pada perubahan pakem (aturan tradisi); atau modifikasi bentuk pertunjukan yang tidak sekedar sebagai seni, namun juga sebuah komoditas (produk). (Wibowo A, dkk., 2019, hlm. 219) Sebagai sebuah seni pertunjukan, tentunya tidak dapat terlepas dari unsur estetika, yaitu "bentuk" terdiri dari struktur koreografi, struktur karawitan, dan penataan rias-busana; "bobot" terdiri dari eksistensi senimannya, konsep garap, dan proses garap; "penyajian" yang terintegrasi. (Ramlan, L. dan Jaja, 2019, hlm. 328)

Pada kultur Jawa, merujuk pada gerak wayang, ragam jenis gerak sangat menentukan tipe karakter dan kepribadian persona. Bahasa rupa 'gerak' yang semula merupakan tata ungkapan luar, melalui perpindahan ruang dan waktu, akhirnya dapat dikembangkan melalui bahasa rupa 'gerak' wayang kulit bayangan di saat pergelaran (Ismurdyahwati, 2007, hlm. 365). Dikelompokkan dalam tiga bagian penting: gestur (bahasa tubuh), transisi (peralihan satu gerakan ke gerakan berikutnya) dan perang (adegan perang). Bahasa Tubuh/ gesture yang digunakan, diperlihatkan di setiap adegan adalah bahasa tubuh formal (Ismurdyahwati, 2007, hlm. 366). Penelitian ini bertujuan untuk mengidentifikasi transposisi kreatif 'gerak' wayang pada film Setan Jawa dalam posisinya sebagai kode kultural yang terkonvensi, yang kemudian dipetakan ke dalam kategori intersemiotika yang melibatkan unsur nonverbal (deverbalisasi) bersifat supersemiotika-artinya, makna disampaikan lebih dari sekadar dua saluran (Gottlieb, 2007, hlm. 25-27); gambar dan gerak. Posisi makidhipuh merupakan salah satu gerakan standar yang biasa digunakan 


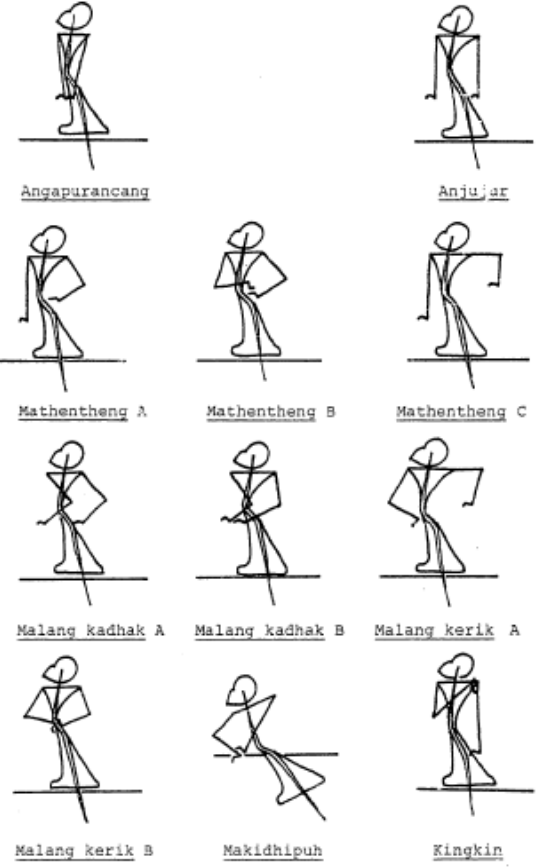

Gambar 2. Gerak Wayang

(Sumber: Roger Long, 1979, Appendix C)

dalam wayang (Long, 1979, Appendix C). Posisi makidhipuh merupakan bahasa tubuh yang unik untuk posisi wayang kulit duduk bersimpuh atau duduk bersimpuh sambil berjalan, terjadi saat tokoh dalam posisi bergerak (bersimpuh sambil berjalan) atau posisi makidhipuh sambil menyembah.

Selain makidhipuh, Roger Long (1979, Appendix C) juga mengidentifikasi adanya gerak standar dalam wayang, yaitu posisi lengan angapurancang, merupakan posisi lengan pada tipe karakter yang lebih tenang, posisi mathentheng yang merupakan bahasa tubuh yang digunakan oleh semua tipe karakter tokoh wayang, baik tokoh berwatak halus, berwatak gagah atau tokoh berwatak kasar, posisi malang kadhak merupakan posisi dasar yang diperlukan untuk gerakan berlari, berjalan, terbang atau perkelahian, dan posisi malang kerik merupakan bahasa tubuh untuk menyatakan sikap melawan atau bersiap-siap menyerang.

\section{METODE}

Penelitian ini merupakan penelitian interdisplin dengan menggunakan pendekatan studi kasus dan analisis dokumentasi. Sebagai penelitian interdisiplin, selain merupakan studi budaya, juga menggunakan pendekatan semiotika dan sosiologi kaitannya dengan menelaah makna yang terbangun oleh gerak wayang karakter pada film. Data yang digunakan adalah film "Setan Jawa" yang diperoleh dari Garin Workshop, serta data pendukung hasil studi literatur yang mendukung, berkaitan dengan penelusuran sejarah sinematik-orkestra, termasuk di dalamnya juga multiliterasi visual dalam produk budaya visual, khususnya film. Data yang dibutuhkan untuk analisis relasi makna dalam penelitian ini akan meliputi data referensi dan data visual.

Data referensi merupakan beragam penelitian yang memiliki irisan kesamaan dengan objek penelitian untuk menjadi acuan penelitian, terutama dalam menentukan kerangka metodologis dan teoritis penelitian ini. Sumber referensi dalam analisis dokumentasi juga akan menentukan posisi penelitian terkait penentuan identifikasi masalah dan tujuan penelitian, yang pengumpulan datanya akan dilakukan secara berkelanjutan sesuai dengan data penelitian. Data visual diperoleh dari dokumentasi berupa pertunjukan sine-orkestra film "Setan Jawa".

Transposisi, translasi atau penerjemahan menjadi salah satu pendekatan studi interdisiplin akademik yang diasumsikan mampu menjembatani dialektika kata-gambar. Transposisi berurusan dengan studi sistematis 
teori, deskripsi dan penerapan penerjemahan, penafsiran dan lokalisasi. Studi Transposisi dan Translasi meminjam banyak dari berbagai bidang studi yang mendukung penerjemahan, termasuk literatur komparatif, ilmu komputer, sejarah, linguistik, filologi, filsafat, semiotika dan terminologi (Gottlieb, 2007, hlm.1-12).

\section{HASIL DAN PEMBAHASAN}

Bahasa memiliki integritas, yang berarti bahwa bahasa menyimpan aturan dan sistemik dan/atau bentuk-bentuk yang teratur dengan capaian tertentu, dengan kata lain, tidak bersifat permanen.Setiaporang dapatmengadaptasikan dirinya dengan gaya berbahasa yang paling mendefinisikan dirinya, meski setiap orang, seperti yang telah di bahas pada bagian sebelumnya, akan memiliki kecenderungan gaya yang mendekati karakter dasar dirinya. Sebagai the constant form, bahasa bukan sesuatu yang 'serta-merta', namun ada kesadaran yang membentuknya menjadi sebuah 'mekanisme', 'keteraturan', 'punya daya adaptasi' terhadap lingkungan sosial.

Budaya mixed media telah banyak mengubah norma dan kultur, termasuk juga persoalan bahasa; kata-dan-gambar. Internet, film, televisi, iklan, video game, dan hibrida seni-tinggi (instalasi, seni pertunjukan) menuntut kemampuan yang terus meningkat untuk memecahkan kode interaksi antara kata dan gambar. Dalam keadaan ini, hubungan kata dan gambar seoalah-olah menjadi penting. Historisitas keterkaitan antara verbal dan visual telah mendasar bagi sejarah beberapa disiplin humanistik. Banyak perdebatan terjadi berkaitan dengan fungsi kata dan gambar baik sebagai konsep yang beridiri sendiri dan/atau konsep yang saling berkaitan, di antaranya paragone atau kompetisi seni pada masa Renaisans, sampai abadke-18berkenaan dengan cita-cita romantisme, sintesis, dan rekombinasi. Hubungan kata-gambar telah menjadi tema berkesinambungan dari pemikiran sastra dan seni sejarah, dan kini, lebih luas lagi pada beragam disiplin ilmu, termasuk di antaranya adalah desain.

Teknologi menciptakan ruang kemungkinan bagi bahasa dalam desain berkembang semakin luas. Dalam desain, bahasa merupakan 'ekspresi diri' dan 'persepsi'. Bahasa dalam desain dapat diapresiasi secara berbeda karena adanya pengaruh sensibilitas dan kemampuan penginderaan setiap orang sebagai hasil perseptual persona dalam memahami realitas, termasuk juga merupakan cara adaptasi persona terhadap budaya yang dihadapinya dalam tatanan ragam relasi sosial. Sumber informasi baru yang tersedia melalui internet dan dalam aplikasi perangkat lunak menyajikan kita dengan lapisan kata dan gambar yang terus bermutasi. Kata-kata dan gambar menjadi dapat mewakili satu dan dengan yang lainnya, melibatkan emosi dan loyalitas atas nilai yang terinternalisasi dalam diri persona sampai melibatkan proses memorialisasi, bahkan ekspresi multi-media dapat menciptakan oposisi kata-gambar terkait dengan biner ideologis kuat lainnya: maskulinitas versus feminitas, waktu versus ruang, abstraksi versus materialitas, dan seni versus alam.

Berkaitan dengan keterkaitan kata dan gambar dalam bahasa pun memunculkan perdebatan berkaitan dengan peran 
Tabel 1. Transposisi ‘Gerak' Wayang pada Film "Setan Jawa"

(Sumber: Gambar Film "Setan Jawa" karya Garin Nugroho (2017); rujukan gerak wayang diadaptasi dari Roger Long (1979))

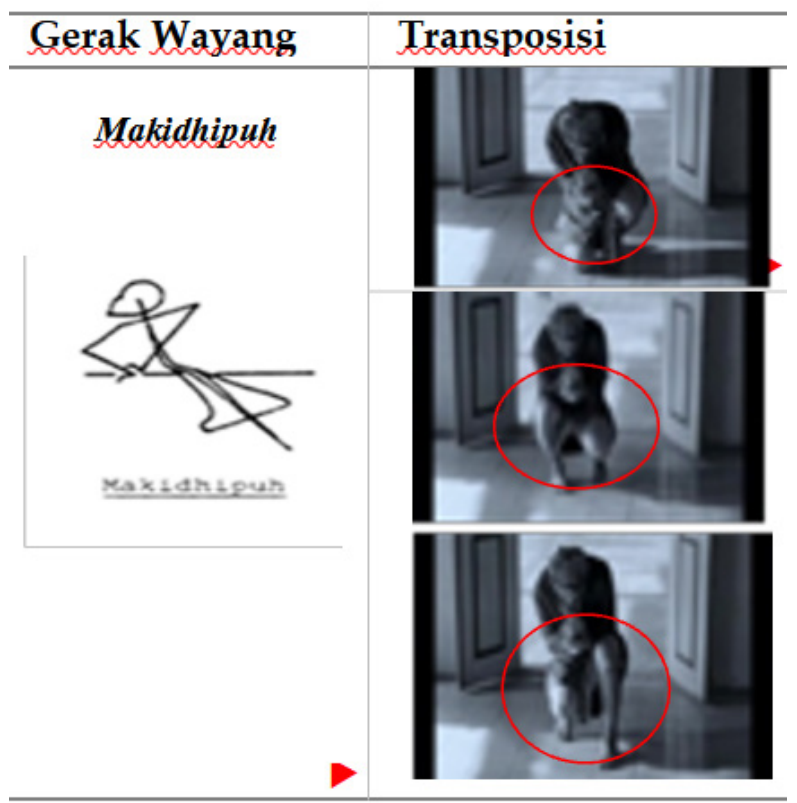

penerjemahan satu dan lainnya, terkait kata dan gambar sebagai tindak komunikasi; apakah yang satu bertindak sebagai suplemen atau 'ilustrasi' untuk kata-kata, atau sebaliknya, termasuk bagaimana kemudian bahasa yang telah diterjemahkan menjadi imaji yang lebih kongkrit secara visual sanggup menyasar pada konsep diri persona dan termaknai secara tepat sebagai identitas dirinya.

Secara historis, studi translasi dan transposisi (terjemahan) telah lama bersifat preskriptif (memberi tahu para penerjemah bagaimana menerjemahkannya), sampai pada titik di mana diskusi terjemahan yang tidak bersifat preskriptif pada umumnya tidak dianggap sebagai terjemahan sama sekali. Ketika sejarawan studi penerjemahan menelusuri pemikiran awal Barat tentang penerjemahan, misalnya, mereka paling sering menetapkan permulaan pada ucapan Cicero tentang bagaimana dia menggunakan terjemahan dari bahasa Yunani ke bahasa
Latin untuk meningkatkan kemampuannya dalam oratoris-uraian awal tentang apa yang akhirnya disebut sebagai 'terjemahan akaluntuk-akal'.

Sejarah deskriptif penerjemah di Mesir yang disediakan oleh Herodotus beberapa abad sebelumnya biasanya tidak dianggap sebagai studi terjemahan-bisa jadi karena tidak memberi tahu penerjemah bagaimana menerjemahkannya. Diskusitentang bagaimana menerjemahkan, berasal dari terjemahan sutra Buddha selama Dinasti Han di Cina.

Analisis transposisi kreatif gerakan wayang di film "Setan Jawa", diambil dari adegan awal munculnya masalah dalam cerita yaitu saat Ibu (Dorothea Quinn) menolak lamaran Setio (Heru Purwanto).

Dari Tabel 1, dapat diidentifikasi gerak wayang makidhipuh yang khas yang divisualisasikan oleh Setio dengan duduk bersila dan kemudian jalan mundur sambil jongkok dengan posisi tubuh berjongkok dan kepala menunduk.

Dalam presentasi diri dalam kehidupan sehari-hari, Goffman (1959, hlm. 13) menguraikan kerangka kerja konseptual di mana setiap kesempatan untuk-wajah interaksi dapat ditafsirkan sebagai kinerja teater. Goffman percaya bahwa gagasan bahwa hidup adalah seperti permainan yang tidak pernah berakhir di mana setiap orang adalah seorang aktor dan ketika kita dilahirkan, kita didorong ke panggung yang disebut kehidupan seharihari dan bahwa sosialisasi kita terdiri dari belajar bagaimana memainkan peran yang ditugaskan dari orang lain. Goffman (1959, hlm. 16) menggunakan metafora dari teater di atas panggung, para aktor dan penonton untuk 
mengamati dan menganalisis seluk-beluk interaksi sosial.

Dalam konsep dramaturgi diri terdiri dari berbagai bagian yang orang bermain dan tujuan utamanya adalah untuk menyatukan aktor sosial sendiri berbeda dengan cara yang berbeda yang menciptakan dan mempertahankan kesan khusus untuk khalayak yang berbeda mereka. Mengacu pada Goffman (1959, hlm. 16-17), transposisi kreatif terjadi di Setan Jawa film menciptakan frase 'manajemen kesan', yang pada tahap ini berlaku mekanisme tanda untuk menampilkan diri kepada orang lain; untuk membangun asumsi umum tentang karakter dan kepribadian seseorang berdasarkan orang fisik atau etnis.

Bahasa tubuh adalah gesture yang mempunyai makna untuk mengungkapkan ekspresi (Sri Rustiyanti, dkk., 2020, hlm. 454). Makidhipuh pada transposisi 'gerak' wayang yang dilakukan secara kreatif dalam film "Setan Jawa" juga mewakili status sosial yang berbeda dari masing-masing karakter. Intersemiotik berpotensi membuka ruang untuk transposisi kreatif, transmutasi kode budaya dalam gambar dalam gambar film dalam lapisan studi filosofis lebih mendalam. Setiap 'gerak' yang telah dialihkan pada pertunjukan wayang menunjukkan bahwa cara kita bertindak dalam hidup tidak pernah konstan; tidak peduli apa dan siapa, bagaimana 'diri' bersosialisasi selalu dipengaruhi oleh mana sebuah ruangan di mana seseorang, dengan siapa bersama-sama, dan kapan harus berada di sana.

Goffman, mengadaptasi Burke, menyatakan bahwa dalam interaksi sosial, semua 'diri' adalah seorang aktor dan dunia adalah panggung. (Goffman, 1959, hlm. 17-24).
Akan tetapi, tanda yang dijalin ke dalam proses antar-semiotik tentu tidak dapat dipisahkan dari cengkeraman gerakan boneka, atau pakem mereka, yang mewakili budaya 'diri' Jawa pada berbagai jenis hubungan sosial yang dihadapi dalam kehidupan nyata, bahwa salah satu akar bermuara pada prinsip harmoni dan penghormatan yang telah menjadi ciri khas kepribadian orang Jawa. (Susetyo, 2014, hlm. 49) ini berarti, bahwa transposisi kreatif 'gerak' wayang pada film Setan Jawa tidak boleh terpaku hanya pada keindahan visual, namun juga tetap harus berpegang pada konteks yang imajiner (Haryadi, dkk., 2013, hlm.53); dalam kaitannya dengan transendental dan imanensi dari kepribadian Jawa.

Dalam film Setan Jawa, potensi ini kemudian, menjadi sebuah tawaran baru, sebuah estetika khas bagi pengembangan multiliterasi visual untuk mencapai kompetensi yang dibutuhkan pada Indonesia 4.0 yaitu Kompetensi Pemahaman Konsep (Conceptual Understanding) berhubungan dengan kemampuan seseorang untuk memiliki pemahaman tentang berbagai ilmu pengetahuan, Kompetensi Berpikir Kritis (Critical Thinking) merupakan kemampuan mendayagunakan kemampuan berpikir dan kemampuan menalar dan memberikan apresiasi (Dewi, A.K., 2019, hlm. 5-6), dalam hal ini, adalah berkaitan dengan identitas kultural etnis tertentu yang mengandung nilai-nilai luhur falsafah hidup yang harus ditransmisikan antar generasi dalam ragam tatanan interaksi sosial dalam masyarakat. 


\section{SIMPULAN}

'Gerak' wayang menunjukkan deskripsi konseptual 'diri' mereka sebagai orang Jawa tergambarkan dalam frase-frase menurut ungkapan masing-masing. Dalam hal penghayatan 'diri' di kehidupan nyata, subjek mengimplementasikan apa yang mereka konsepkan sebagai karakteristik dari 'diri' masing-masing ke dalam sikap dan perilaku sehari-hari, terwujudkan melalui salah satunya adalah gerak tubuh.

Pada film "Setan Jawa", kemunculan transposisi kreatif menghasilkan makna dengan modifikasi luas, yang juga merupakan sarana mengadaptasi penempatan bahasa sumber dalam konteks baru untuk tujuan tertentu, subversi bahasa verbal, proses intersemiosis, yang merujuk pada operasi metalinguistik searah di mana karakter linguistik telah dipindahkan atau diubah secara kreatif menjadi elemen kode dan nonlinguistik.

Dengan pendekatan sinematik-orkestra yang memadukan beragam tanda-tanda literasi mulai dari gerak, bunyi, kata-dangambar, sistem konstruksi visual pada film Setan Jawa meskipun merupakan film bisu, namun mengandung pendekatan literasi (literacy approach) dengan dimensi pembelajaran multiliterasi yang dapat menggabungkan multi modal literasi baik sumber oral, audio, visual, spasial, gestural, dan/atau audio visual dalam penerapannya pada film sebagai saluran komunikasi visual.

Meski demikian, masih dibutuhkan penelitian lebih lanjut sebagai kajian mendalam pada area 'gerak' sebagai kode bahasa dalam film yang menentukan model budaya tertentu; dalam hal ini, kode gerak pada film "Setan Jawa" sebagai sarana wacana edukasi budaya dan diskursus budaya tentang identitas budaya etnis Jawa.

\section{UCAPAN TERIMA KASIH}

Terima kasih diucapkan kepada Garin Nugroho (Garin Workshop) atas izin yang diberikan untuk menggunakan dokumentasi film “Setan Jawa" dalam penelitian ini.

\section{DAFTAR PUSTAKA}

Adisasmito, Nuning Y. D. (2012). Wujud Visual Belasunda, R. et al. (2014). Hibriditas Medium pada Film Opera Jawa Karya Garin Nugroho sebagai Sebuah Dekonstruksi. J. Vis. Art \& Des ITB: 6 (2), 108-129.

Bordwell, D., dan Thompson, K. (1997). Film Art: An Introduction, 5th Edition. New York: The McGraw-Hill Companies.

Budiman, C., Abdullah, I., dan Simatupang, G.R.L., Opera Jawa [Requiem from Java]: A Semiotic Narratology Perspective, K@ta: DOI: 10.9744/kata.15.1, 33-38

Deleuze, G. (1986). Cinema 1 The MovementImage. Minneapolis: University of Minnesota Press.

Dewi, A.K. (2019). Pengembangan Kompetensi Multiliterasi Desain Berbasis Pada Penerapan Tradisi Komunikasi Di Era Indonesia 4.0. Jurnal Desain Indonesia: 1 (1), 1-6.

Dewi, A.K. (2019). Peran Film Sine-Orkestra Dalam Komunikasi Grafis Sebagai Media Diskursus Budaya: Studi Kasus Film Setan Jawa Karya Garin Nugroho. Prosiding Seminar ANIMASI DAN VISUAL MEDIA DIGITAL Tema: Eksplorasi Cerita Nusantara, Fakultas Seni Rupa 
Institut Kesenian Jakarta, 70-74.

Dokumentasi Pertunjukan Film Setan Jawa. Diakses pada 29 Mei 2019 dari www. facebook.com/setanjawamovie

Goffman, E. (1959). The Presentation of Self in Everyday Life. London: Penguin Group.

Gottlieb. H. (2007). Multidimensional translation: Semantics turned semiotics. In S. Nauert \& H Gerzymisch-Arbogast (Eds.), Proceedings of the Marie Curie Euroconferences MuTra: Challenges of multidimensional translation, (Online) EU-High-Level Scientific Conference Series. diakses pada 20 Mei 2019 dari http://www.euroconferences info/ proceedings/2005Proceedings/2005_ Gottlieb_Henrik.pdf, 1-29.

Hall, E.T. (1976). Beyond Culture, New York: Anchor Book, 15-20, 71-78.

Hall, S. (1992). The Question of Cultural Identity in Modernity and Its Futures, Cambridge: Polity Press in association with the Open University, Volume Understanding Modern Societies: An Introduction, 277-280.

Haryadi, T., Irfansyah, Santosa, I. (2013). Implementasi Teknik Sabetan Melalui Kinect (Studi Kasus Pengenalan Gerak Wayang Kulit Tokoh Pandawa). Techno.COM: 12 (1), 51-64.

Irfansyah dan Sunarto, P. (2013). Kreativitas Kode Visual Golek Asep Sunandar Sunarya dalam Media TV. Wimba, Jurnal Komunikasi Visual \& Multimedia: 5 (1), 15-26,

Ismurdyahwati. (2007). Kajian Bahasa Rupa Berdasar Rekaman Video Pergelaran Wayang Kulit Purwa dalam Lakon 'Parta Krama'. J. Vis. Art. ITB: 1D (3), 364-390.

Long, R. (1979). The Movement System in Javanese Wayang Kulit in Relation to Puppet Shadow Type, Appendix C. (Ph.D). University of Hawaii.

Ramlan, L., dan Jaja. (2019). Estetika Tari Réndéng Bojong Karya Gugum Gumbira. Panggung: 29 (4), 328-342.

Rustiyanti, S., Listiani, W., Dila Sari, F., dan Gede Surya Peradantha, I. B. (2020). Literasi Tubuh Virtual dalam Aplikasi Teknologi Augmented Reality PASUA PA. Panggung: 30 (3), 454-.
Sugiharto, B. (ed.). (2013). Untuk Apa Seni?. Bandung: Matahari.

Susetyo, DP, B. (2014). Konsep Self dan Penghayatan Self Orang Jawa. Psikodimensia: 13 (1), 47 - 59.

Wibowo, A., Priyatna, A., dan Sobarna, C. (2019). Modifikasi Wayang Topeng Malangan di Padepokan Asmoro bangun, Kedungmonggo Pakisaji, Malang. Panggung: 29 (3), 219-236. 